\title{
Eu sou mais indie que você! As disputas do indie rock para se afirmar como rock autêntico
}

Nadja Vladi Gumes ${ }^{1}$

\section{RESUMO}

Este artigo é um recorte da minha tese de doutorado que teve como proposta desenvolver um modelo compreensivo para análise dos processos de classificação que envolvem práticas musicais. Partindo da autonomeação de críticos e fãs de rock, que assumem suas práticas como pertencentes ao gênero indie rock, o texto aborda os sistemas classificatórios do mundo da música como um complexo processo de comunicação que serve de base para a partilha de experiências musicais, valores ideológicos, lógicas comerciais e trocas sociais presentes na produção, no consumo e na circulação dos produtos midiáticos. Assim, procura-se observar como o gênero cultural indie rock configura tensões, disputas e negociações que envolvem as inter-relações entre autonomia criativa e estratégias de mercado dentro da indústria da música. Questões como circular em selos independentes, estar fora de programas de televisão, usar a internet, não fazer parte do mainstream, gravações com a poética de home studio, uso de muitas guitarras, de vocais suaves, de letras mais existencialistas, do hibridismo musical, do minimalismo, das distorções, da autonomia criativa, da originalidade são algumas marcas que fazem com que essa comunidade perceba e identifique determinadas sonoridades como indie rock.

Palavras-chave: gêneros; consumo cultural; valoração; indie rock.

I'm more indie than you!

The indie rock bickering to assert itself as authentic rock

\section{ABSTRACT}

This article is a part from my thesis whose purpose to develop a comprehensive model for analysis of processes that involve labeling the cultural practices of music. Starting from the self-appointed critics and rock fans, who take their practices as belonging to the indie rock genre, the paper addresses the processes of labeling the music world as a complex communication process that underpins the sharing of musical experiences, ideological values, social divisions, and business rationale present in the production, consumption and circulation of media products. Issues such as that of circulating independent labels, existing outside of mainstream television, using the internet as a form of circulation, not being part of the mainstream, home recording, use of many guitars, soft voices, more existential lyrics, musical hybridism, minimalism, distortions, creative autonomy, and originality are some of the traits that enable this community to perceive and identify certain sounds as indie rock and associate it with the idea of the genre.

Keywords: genres; cultural consumption; valuation; indie rock

1 Nadja Vladi Gumes é professora adjunta do Centro de Cultura, Linguagens e Tecnologias Aplicadas da UFRB e docente permanente do PPGCOM/UFRB. 
Que música você está ouvindo? Que som é esse? As perguntas com as quais começo este artigo tem como objetivo refletir sobre a importância das classificações nos processos culturais contemporâneos, especificamente na produção, consumo e circulação da música. Percebemos que dentro do ambiente das indústrias culturais ainda prevalece a lógica de reconhecimento para gerar determinadas expectativas, o que nos mostra a importância do processo classificatório como um modo de mediação entre as estratégias produtivas e a recepção, uma orientação fundamental para nos guiar na leitura dos produtos culturais. Reconhecemos os produtos por suas rotulações, e isso gera uma reação do espectador, cria expectativas e um prazer sugerido pelo reconhecimento. A música como fenômeno comunicacional envolve diversas disputas, tensões, valores e gostos. MartínBarbero (2001, p. 311), em seu livro Dos meios às mediações, argumenta a importância do gênero nos processos de mediação: "Os gêneros (...) constituem uma mediação fundamental entre as lógicas do sistema produtivo e as do sistema de consumo, entre a do formato e a dos modos de ler, dos usos". Dentro desta perspectiva, as condições de produção e reconhecimento dependem das codificações dos gêneros colocadas por Barbero no seu Mapa das Mediações. Mas devemos salientar que os gêneros não são uma categorização simples e facilmente identificáveis porque são modelos dinâmicos e estão em constante mutação, deslocamento e negociação, por isso adotamos, neste artigo, o uso do termo gênero cultural porque percebemos "o gênero como uma estratégia de comunicabilidade" (GOMES, 2011, p.114).

Para Itania Gomes, o conceito de gênero deve ser utilizado de forma que possibilite "tanto o reconhecimento de regularidades e especificidades de formas culturais, quanto o reconhecimento de um modo distinto de configurar a relação comunicativa". (GOMES e ARAÚJO, p.109, 2015). Deste ponto de vista, o gênero é visto como uma categoria cultural que possibilita ser articulado com o "contexto cultural, social e midiático" (GOMES e ARAÚJO). Partimos da perspectiva que o gênero, formulado desta forma - como uma categoria cultural, e não apenas como um classificador, é um conceito que nos permite entender as implicações sociais, ideológicas e sociais no processo de comunicação da música. Como coloca Gomes e Araújo "gêneros mobilizam disputas, valores, julgamentos de gosto, práticas políticas, culturais e econômicas". (2015, p. 109). Posições que possibilitam pensar os fenômenos culturais a partir das mais diversas práticas: "criativas, econômicas, sociais, tecnológicas, institucionais, industriais e interpretativas". (GOMES e ARAÚJO apud EDGERTON; ROSE, 2015. P. 110). Para Gomes \& Araújo (2015):

\begin{abstract}
Analisados sob a perspectiva do conceito de gênero, um produto ou conjunto de produtos são dispositivos que conectam historicamente matrizes da cultura e formatos da indústria (do audiovisual) e lógicas do sistema produtivo, com suas estruturas e suas dinâmicas, às competências de diversos grupos sociais. (p.111)
\end{abstract}

Nesse caso, podemos entender que uma prática musical como o indie rock, por exemplo, constrói uma dinâmica que o conecta dentro de uma lógica do sistema produtivo que passou a se chamar indie rock e não apenas rock. Nesta perspectiva, este artigo traz reflexões sobre o indie rock como um gênero cultural, percebendo como esta prática musical constrói uma estética conectada a uma determinada lógica de consumo, de performance, de usos, de gostos e de produção de sentidos.

\section{De onde vem o indie}

Para entender o que passa a ser denominado como indie rock no final dos anos 1980 precisamos fazer um retorno ao ano de 1967 nos Estados Unidos, na cidade de Nova York, onde a banda Velvet Underground, formada por John Cale, Lou Reed, Sterling Morrison e Mo Tucker, lançava o seu álbum de estreia Velvet Underground and Nico, que tinha nos vocais de algumas canções a cantora e modelo alemã Nico. Considerado um marco para o rock (tanto quanto Sgt. Peppers [1967], dos Beatles, ou Pet Sounds [1966], do The Beach Boys), mas um fracasso de vendas, o grupo apresentava canções que trabalhavam com o mínimo de instrumentos 
e muita experimentação melódica. A capa, uma banana enorme em um fundo branco, era assinada por Andy Warhol (que também produzia o grupo), artista-símbolo do pop art, que pensou na banana como uma forma de criar uma concepção fálica inspirada nas letras de Lou Reed sobre sexo. Com turnê por pequenas casas nova-iorquinas, no vocal uma cantora que cantava com sotaque, Velvet começava a forjar uma poética que influenciou artistas como David Bowie, The Stooges, o movimento punk e todas as bandas que surgiram nos anos $1980 \mathrm{sob}$ o rótulo de indie rock. $\mathrm{O}$ álbum rompe, de certa forma, com a visão colorida do mundo hippie, com um produto do lado sombrio do submundo de Nova York (EUA). Um som lento, distorcido, urbano e marginal. Há nas melodias e nas letras uma inquietação, um ar soturno da vida.

Os críticos viam a música do Velvet como nova, experimental, "artística", considerada a vanguarda do rock, que trazia valores novos para o gênero. Bannister (2006) coloca que "o apelo do Velvet é usualmente definido como voltado para uma classe média branca formada por grupos boêmios, para os quais a arte é uma ideologia central" (BANNISTER, 2006, p. 44). Ao desafiar ideias tradicionais da performance do artista no palco, com projeções de vídeos durante os concertos, ênfase para a simplicidade e o minimalismo das canções, músicas com letras inspiradas na literatura beat que estimulavam sentimentos sobre a tristeza, a decadência, a androgenia, os vícios, Velvet rompia com uma tradição do machismo do rock e trazia para o gênero algo mais teatral, a performance da arte, valores que acabaram sendo associados pelo indie rock do final dos anos 1980.

A importância do grupo para o indie rock está em marcas que consolidaram a prática musical nos anos 1980: a voz arrastada de Lou Reed, o estranhamento do som produzido por uso acentuado de feedbacks eletrônicos, que davam às canções uma paisagem urbana, valorização da base rítmica que se repetia de forma minimalista. E a guitarra de Cale com muitas distorções. Outro ponto importante é perceber que o disco foi pensando como uma obra de art rock, com as melodias casando perfeitamente com as letras e vendendo a ideia de histórias nova-iorquinas.

Ao apontar seu olhar para uma música que cria uma tensão com o rock hegemônico, Velvet se posiciona no mercado como uma banda alternativa ao estabelecido, que faz uma música "criativa", que se coloca em uma posição de distinção ao que é comercial, trazendo para si a ideia de autonomia criativa no rock que vai influenciar a cena de indie rock de todo o mundo, solidificando um mercado de nicho. Em entrevista a Bill Flanagan (1996), Lou Reed conta como percebia o rock naquele momento:

\begin{abstract}
O meu interesse desde o tempo dos Velvets tem tido sempre a mesma estrela-guia: a ideia de pegar o rock and roll, com todo o seu formato pop, e dar a ele uma forma adulta. (...) Em primeiro lugar tem que ser rock and roll. De cima a baixo, uma boa canção de rock. Não um enxerto, uma mutação canhestra, bisonha. Tem que preservar a alma, a raiz do rock, ligada ao baixo, a bateria. (FLANAGAN, 1986, p. 304).
\end{abstract}

Pode-se perceber que Lou Reed reintegra aqui os valores básicos do rock, mas propondo elementos novos que vão conferir prestígio e demarcar a autenticidade do gênero através de simplicidade e a rebeldia, desde o seu surgimento nos anos 1950. Ele traz novidades, mas se afirma sempre como rock, mostra como é importante se posicionar dentro do que considera a raiz do rock, o baixo, a bateria, a malícia, a simplicidade.

Os anos 1960 do Velvet vão ecoar nos anos 1980, quando o rock vivia a ressaca dos póspunk dos Sex Pistols e Ramones, e os roqueiros estavam interessados em misturar o som cru e a ideologia do "faça você mesmo" do punk rock com as experimentações sonoras de um rock de vanguarda. A época era propícia com a popularização do home studio mostrando a viabilidade de gravações caseiras com qualidade decorrente de um acesso mais democrático à tecnologia musical. A estrutura do home studio torna-se possível por conta de equipamentos como gravadores, microfones e sintetizadores mais baratos, mídias de armazenamento digitais e uso de sample que deixavam todo o processo a um custo menor. Este novo cenário permitiu que artistas e gravadoras tivessem condições básicas de produção e controle sobre as gravações. A democratização da tecnologia do sintetizador, a ampliação da cultura do 
computador são transformações fundamentais para a organização da chamada cena musical independente. Nesse momento, gravadoras/selos independentes passam a promover e produzir artistas tendo como parâmetro a autonomia criativa. A facilidade para montar um home studio possibilitou experimentar e criar sem os custos altos de um estúdio profissional e fez surgir uma determinada poética de fazer música com a chamada low-fidelity (low-fi) $)^{2}$.

$\mathrm{O}$ discurso do indie rock passa a agregar inovação, crítica ao estabelecido (TOSTA DIAS, 2000), criando um espaço dentro da lógica mercadológica da indústria da música cujo consumo dos produtos culturais se estabelece a partir da tensão permanente entre o processo criativo e o mercadológico. Esse ambiente proporcionado pelos baixos custos de tecnologia coloca em pauta novas práticas sociais e novas sonoridades. $\mathrm{O}$ que era imperfeição do estúdio caseiro, como distorções e uma baixa qualidade de gravação, torna-se uma forma de fazer rock. Dentro deste contexto, discos de rock produzidos nos anos 1980 com baixo custo, buscando uma performance mais espontânea, tornam-se parte de uma característica de música mais artsy (com a pretensão de ser arte) e menos comercial. O home studio torna-se uma ideologia, uma poética, uma posição de uma sonoridade $l o w$ - $f$ e percebemos como suportes e artefatos tecnológicos são mediadores fundamentais das práticas culturais. Sem o home studio, dificilmente existiria o indie rock.

\section{Sonoridade, valores e gostos}

A sonoridade do indie rock é complexa e diversa: guitar bands, como Sonic Youth e brincando de deus; outras que flertam com o ska, como a Vampire Weekend; aquelas que dialogam com o punk rock, como Pixies. Mesmo assim nos interessa perceber nuances musicais estabelecidas entre elas como sonoridades posicionadas como contra-hegemônicas, seja pela distorção, pelos valores étnicos, pelos aspectos básicos da produção sonora em detrimentos das grandes produções fonográficas e também pela capacidade de abertura que o indie rock tem em dialogar com outras práticas musicais. Um dos instrumentos importantes e de destaque para o gênero é a guitarra, mas também percebermos as gravações em baixa fidelidade, a preferência por tecnologia antiga e o uso de distorções como elementos que ajudam a esboçar uma musicalidade indie rock, uma estética musical que tem como "pano de fundo" um contexto econômico, no qual as bandas não tinham dinheiro e só podiam alugar o estúdio por poucas horas, portanto, faziam valer logo a primeira gravação feita com instrumentos e equipamentos baratos. Estas condições limitavam a sonoridade e se transformaram em valores de autenticidade do gênero cultural. Para Bannister:

O minimalismo musical tornou-se uma faceta do indie rock, o seu estilo que repercute nos volumes das guitarras, sempre com uma mixagem alta, obscurecendo os vocais e dando um efeito de música ao vivo, herança do punk rock (BANNISTER, 2006, p. 70).

O que percebemos é que a poética indie rock incorporou e se transformou tendo como base uma limitação econômica para sua sonoridade e uma posição contrária ao estabelecido como valoração.

Os gêneros podem ser classificados pela sonoridade, temáticas, elementos imaginários, clichês harmônicos e melódicos e elementos intrínsecos, como faixa etária, estilo de vida, mas também por ideologia, e contextos sociais e históricos. Ao utilizar estratégias que funcionam como filtros para se posicionar dentro de um gênero, bandas mantêm a circulação para uma

2 Low-fi ou baixa fidelidade é um termo utilizado para descrever uma gravação de som que contém falhas técnicas, como distorções, ruído de fundo, ressonância, ênfase em determinadas frequências. O termo é usado em contraste com highfidelity (alta fidelidade), que se refere aos equipamentos de som que reproduz músicas com muita precisão. Low-fi é usada como estratégia discursiva de determinados gêneros e cenas musicais. Em algumas gravações de indie rock, por exemplo, o que era uma baixa qualidade transforma-se em poética e mesmo em gravações feitas em alta fidelidade simula-se a baixa fidelidade por razões estéticas. A qualidade baixa da gravação passa a ser uma posição de autenticidade dentro do indie rock. 
determinada audiência. Fabbri (1980) coloca que as regras complexas tornam o gênero mais rico e duradouro, mas os "sistemas pobres" possibilitam mudanças mais perceptíveis dessas regras. As guitarras e os estúdios baratos, uma masterização que afetava os elementos rítmicos, o uso de pedais com guitarras dissonantes que apagavam os vocais são situações iniciais do indie rock que vão sendo absorvidas como uma forma de se fazer um tipo de rock e acabam sendo incorporadas como marcas estilísticas do indie rock.

O uso de notas repetidas, cordas com vibração, muito efeito de reverberação, poucos elementos rítmicos, guitarristas que não são virtuosos, canções harmonicamente simples e repetitivas, vocais monótonos vão se concretizando como o ideal indie rock para uma comunidade de conhecimento. A música é simples, direta, com ênfase para reverberações. As canções são pessimistas, intelectuais, individualistas, corporificado uma música para ser ouvida como expressão artística, e não descartável e feita para vender. As limitações técnicas e econômicas, o improviso, são elementos que vão construído este idealismo indie rock: "A idealização de incompetência servindo como uma importante função ideológica" (BANNISTER, 2006, p. 80). As limitações técnicas, as posições ideológicas (resistência, autonomia, autenticidade) fazem parte das representações do indie rock e se transformam em suas características, em uma codificação estética.

Para Frith (1996), o gênero é uma configuração ideológica e social, portanto, ao defini-lo devemos levar em consideração o conteúdo, as implicações ideológicas e o gosto musical. Por isso ele propõe pensar da seguinte perspectiva: a) convenções sonoras (o que você escuta); b) convenções de performance (o que você vê); c) convenções de embalagens (qual tipo de música é vendida); e d) os valores incorporados (a ideologia da música). Uma canção não é definida apenas por uma forma ou estilo de um texto, mas pela percepção da audiência, do significado que ela produz no momento da performance, porque as classificações descrevem o sentido que a música tem para os ouvintes, como ela se comunica com a sua audiência. Quando Frith coloca que a posição do gênero está ligada a questões musicais (o que você está ouvindo) e questões de mercado (quem compraria isso?), para o autor, dividir a música em gêneros tem como objetivo organizála em três momentos: o ato de consumo, o ato de executar e o ato de ouvir. Ao analisar um determinado gênero, Frith propõe que ele possui estratégias discursivas diferentes e possibilita experiências musicais distintas que devem ser consideradas na análise de produção de sentido. Os gêneros descrevem não apenas quem são os ouvintes, mas também qual o sentido que esta música tem para eles.

Hesmondhalgh explica que o termo indie tornou-se amplamente usado no ambiente da música quando passa a descrever a nova fase da política cultural alternativa do pop rock britânico, na qual se busca um caminho entre mercado e autonomia criativa, capitaneada em parte por uma crise econômica nos anos 1980. "Indie descreve um cenário mais estreito de sons e olhares" (HESMONDHALGH, 1999, p. 38). As bandas que se comunicam como indie rock (britânicas e americanas) são substancialmente formadas por jovens garotos brancos, com pouco foco no ritmo ${ }^{3}$, ênfase nas guitarras distorcidas e em letras sensíveis e inteligentes. Vivendo na contradição de ter domínio da produção criativa, mas buscando sucesso profissional, o indie sempre se mostrou contraditório, criando barreiras ao seu redor para não ser conhecido, nem consumido por todos, adotando uma narrativa exclusivista para sua música, artistas e audiência e construindo um mercado de nicho. Neste ambiente surge, em 1981, a banda nova-iorquina Sonic Youth, considerada a gênese do que passou a ser chamado de indie rock, com uma sonoridade fundamentada em experimentações sonoras, distorções, uso diferenciado das afinações das guitarras e que faz uma ressignificação da filosofia punk do "faça você mesmo", do barulho da The Stooges e do minimalismo da Velvet.

Ao refletir sobre a trajetória de duas bandas entendidas por fãs, críticos musicais, blogueiros e músicos como indie rock, buscamos perceber a

3 Grupamento de sons musicais, principalmente por meio de duração e ênfase (SADIE, 1988, p. 788). 
importância do gênero cultural para o processo de comunicação da música e sua sociabilidade, dessa forma este artigo lança mão de uma análise cultural dos álbuns de duas bandas: a americana Sonic Youth e a baiana brincando de deus. O que percebemos neste debate em torno do uso das classificações para a produção, consumo e circulação das práticas musicais é que há uma necessidade de delimitação de espaço dentro do rock para que determinadas estilos tenham sentido, e, para isto, importa qual a posição que cada banda e artista ocupa neste universo. Portanto, quando uma banda e fãs afirmam que fazem parte de uma determinada comunidade musical, eles vão delimitar valores, marcas sonoras, identidades, gostos, subjetividades que fazem parte de estratégias de posicionamento no mercado da música que se afinam com o que eles identificam, por exemplo, como indie rock.

As duas bandas selecionadas aqui justificamse por buscar uma compreensão de como se coloca a autenticidade para elas em lugares (geográficos e simbólicos) diferenciados. Ambas se posicionam dentro da lógica de tensão entre o processo criativo e a lógica mercadológica e sempre colocam o discurso da autonomia de seus trabalhos como fundamental no processo artístico, musicalmente adotam a postura de um rock cru, sem afetações, cheio de distorções e experimentalismos. Tentamos compreender como articulam estratégias de autonomia dentro do mercado de consumo cultural a partir das seguintes questões: o que é autenticidade para uma banda indie da Bahia ou dos Estados Unidos? Quais as configurações de uma banda que circula de forma completamente independente de outra, que tem a poética independente, mas circula pelo mainstream ${ }^{4}$ ? O que tem de indie e o que tem de rock? Qual o sentido de autonomia para estes artistas?

\section{O barulho que é arte $>$ Sonic Youth}

Thurston Moore e Lee Ranaldo formaram a Sonic Youth, com a baixista Kim Gordon, em 1981. É também no início dos anos 1980 que surge a new wave, uma música melódica que valorizava as letras e um bom humor intelectualizado, usava sintetizadores e bateria eletrônica e tinha como representantes bandas como The Police, Elvis Costello, B-52s, Talking Heads. Era um rock com influência da música disco, do reggae e foi bem capitalizado com o surgimento da MTV. No Reino Unido, a new wave teve uma versão mais sombria, com o gothic rock do Joy Division e The Cure. A década de 1980 é também marcada pelos sucessos Billie Jean (1982) e Beat (1983), de Michael Jackson. E com Madonna alcançando o topo das paradas com Like a Virgin, em 1984. Moore e Ranaldo chegaram a Nova York (EUA) durante o auge do pós-punk, o que fez com que a dissonância de bandas como The Stooges ${ }^{5}$ fosse muito bem capitalizada pelo grupo, que descartou as batidas eletrônicas da new wave. $O$ álbum de estreia da Sonic Youth, Confusion Is Sex, saiu dois anos depois de sua estreia, em 1983, com uma sonoridade influenciada pelo minimalismo da Velvet e o barulho da Stooges. A primeira faixa, (She's in a) Bad Mood, começa com um som distorcido de guitarra, clima que toma conta de todas as nove faixas do disco original. A capa é um desenho feito por Kim e Thurston, em preto e branco, retirado do cartaz de um show, e apontava já o caminho escolhido pela banda de reconstruir novos sentidos para o rock, abrindo mais espaço para a guitarra e os efeitos produzidos com ela. A Sonic Youth busca um som regressivo do final dos anos 1960, usando o efeito no qual uma nota soa a maior parte do tempo em uma canção, criada a partir de um retorno da guitarra, feito antes por John Cale, em canções como Heroin. Ao mesmo tempo, incorpora a poética do "faça você mesmo" do punk rock, com gravações que soam em baixa fidelidade, feitas em um home studio, e com distribuição independente das grandes gravadoras.

$4 \mathrm{O}$ denominado mainstream (que pode ser traduzido como fluxo principal) abriga escolhas de confecção do produto reconhecidamente eficientes, dialogando com elementos de obras consagradas e com sucesso relativamente garantido (JANOTTI JÚNIOR; CARDOSO, 2006, p. 18).

5 Banda norte-americana de proto-punk formada no final dos anos 1960, liderada por Iggy Pop. Lançou dois discos, The Stooges (1969), produzidos por John Cale, do Velvet, e Fun House (1970). 
O sexto álbum, lançado em 1989, Daydream Nation, pela Enigma Records ${ }^{6}$, saudado pela crítica de revistas como Rolling Stone, The Spin, New Music Express como a obra-prima da banda, é uma tentativa de fazer um trabalho artístico dentro de uma indústria fonográfica que ainda dava as cartas no final do século XX. O disco foi gravado no Greene Street Recording, tendo como engenheiro de som e produtor Nick Sansano, que já tinha trabalho com grupos de hip hop, como Public Enemy. No álbum, SY mantém sua característica em utilizar uma grande variedade de afinações de guitarra pouco ortodoxas, e a utilização de objetos como baquetas e chaves de fenda para alterar o timbre dos instrumentos. Daydream Nation foi recebido por críticos e fãs como uma obra-prima por suas passagens instrumentais explosivas alternando com um som tenso e hipnótico, uma possibilidade de transformar o som punk com o minimalismo do rock da Velvet Underground. O disco, lançado em pleno governo do presidente republicano Ronald Reagan, traz diversas texturas e uma guitarra ruidosa, minimalista, com canções consideradas notáveis pela crítica, como as elogiadas Teen Age Riot e Silver Rocket. O álbum é colocado pelos críticos como um divisor de água no rock dos anos 1980, posicionando o desempenho da Sonic Youth como um diferencial no panorama pop que se estabelecia no pós-punk, trazendo visibilidade ao que passa a ser rotulado como indie rock.

O som da banda é chamado de "a nova estética da cultura juvenil" que associou a energia punk com a desilusão política do final dos anos 1980, com ascensão da direita nos Estados Unidos e a implantação de uma política neoliberal. A canção Teenage Riot, que abre Daydream Nation, é um hino deste momento. Riffs de guitarras cheios de barulhos e microfonias, uma voz sussurrante de Kim Gordon, depois a voz relaxada de Thurston Moore são aspectos que foram absorvidos dentro de uma sonoridade que passaria a ser classificada como indie rock e que estão nesta canção e neste álbum. Para Abebe (2007), ao lado de lançamentos de bandas como My
Bloody Valentine, Dinosaur Jr. e Pixies, o álbum do SY definiu "o vocabulário do indie rock" ao transformar "barulho em arte" com suas guitarras ruidosas e sujas. O Sonic Youth também resgata para o indie rock as capas feitas por artistas, como fez o Velvet Underground. Em Daydream Nation, a capa é a pintura intitulada Kerze, um quadro do artista alemão Gerhard Richter, que é traduzido para Cadle (vela), nome de uma das canções do álbum. A capa tem como base uma foto que o artista fez de uma vela acesa em um fundo branco e preto. Ao usar esta imagem, a banda faz uma associação com um tipo de público que valoriza a interação da música com as artes visuais e propõe um jogo com quem consegue acessar que ali está o diálogo com o trabalho de um artista visual.

$\mathrm{O}$ que se percebe é que aqui entra em vigor um sistema de valores e ideias que passa a ser compartilhado por um grupo social. Sonic Youth é uma banda, segundo a crítica, que preserva sua criatividade, suas experimentações musicais, colocando-se como independente. Os ruídos estranhos, as tessituras dissonantes criaram uma atmosfera singular em Daydream Nation e na história do rock. O controle criativo, o circuito de college radios, o barulho, a qualidade dos riffs de guitarra, a experimentação cercada por melodias bem definidas são características apontadas em Daydream Nation e na Sonic Youth que se tornaram marcas do que passou a ser classificado como indie rock no final dos anos 1980. Fortino (2006) observa que:

\begin{abstract}
Desde 1981, quando gravaram seu primeiro vinil (o EP “Sonic Youth”, lançado em 1982), em nenhum momento os integrantes desta banda cederam às exigências do mercado pop rock. $\mathrm{E}$ nunca $\mathrm{o}$ quarteto nova-iorquino Sonic Youth abriu mão de seu radicalismo na distorção e na experimentação de acordes inéditos no rock. (FORTINO, Leandro, Folhateen, Folha de S. Paulo, 10/07/2006) ${ }^{7}$
\end{abstract}

Ao mesmo tempo, a banda circulava por selos independentes, fazia gravações em low- $f$, suas músicas tocavam nos college radios, fazia 
referência ao folk de Neil Young e ao minimalismo da Velvet Underground. As canções eram ouvidas pelos jovens norte-americanos, tinham letras que mostravam como a atual direção do neoliberalismo econômico conservador tomada pelos Estados Unidos diferia da cultura jovem do país. Considerada uma espécie de antecessora do Nirvana, a Sonic Youth nunca foi uma banda de grandes vendagens, nem de grande sucesso, mas "eles têm sido a banda top da cena indie" (MASON, Jack, SPIN, Julho de 2009). A Sonic Youth afirma-se como uma banda de catálogo, e isto está diretamente conectado à ideia de obra. Portanto, uma obra, ao contrário de um produto descartável, permanece como referência tanto ideológica como mercadológica.

\section{Obsessão por independência > brincando de deus}

Na Bahia, o início da década de 1990 foi particularmente importante para a música produzida no Estado. A cidade vivia a ebulição da chamada axé music ${ }^{8}$, que explodiu em vendagens a partir do final dos anos 1980, com o sucesso de bandas como Cheiro de Amor, Reflexus, Olodum e de cantoras como Daniela Mercury. É neste cenário, precisamente no ano de 1992, que surge em Salvador a banda brincando de deus, seguindo os ideais do indie rock. Enquanto a cidade vivia de ensaios de blocos afro, shows de estrelas da axé music, Messias Bandeira, Cezar, Dalmo e Ruy cantavam em inglês canções melodiosas com guitarras carregadas de distorção e letras sobre uma vida urbana depressiva completamente diferente do clima presente na cidade onde viviam. Tendo como referências as distorções e reverberações da irlandesa My Bloody Valentine, a melancolia dos ingleses da The Smiths e o som distorcido dos escoceses da Jesus and Mary Chain, a banda tornou-se uma influência para o circuito indie rock local e nacional. Declaradamente independente, a brincando de deus foi uma das primeiras a criar o próprio selo (Self Records), filmar os próprios videoclipes, circulando em festivais (inclusive criando o próprio, o Boom Bahia ${ }^{9}$ ), lançando compactos no exterior. Foi a primeira banda brasileira a possuir um site na internet. Por isso mesmo sempre foi festejada como uma militante da cena independente, que "não faz concessões".

Para Alexandre Matias (2001), a brincando de deus foi "um dos mais importantes grupos na consolidação do chamado indie rock brasileiro" (MATIAS, 2001). Ao longo da sua existência, gravou três álbuns: Better When You Love (Me) (1995), Running Live of Your Mind (ao vivo) e brincado de deus (2000). Ao se associar aos valores distintos do rock hegemônico produzido no Brasil nos anos 1980/1990, a banda enfatiza seu espaço como independente e ofereceu ao público uma resistência no ambiente do consumo musical. Dessa forma, fez uma oposição também ao movimento manguebeat (oriundo de Recife), que misturava o peso das guitarras com samples e música regional. Assim como a carioca Pelvs, a brincando de deus ajudou a consolidar o que era o indie rock brasileiro nos anos 1990, enfatizando o uso de guitarras altas e distorcidas, canções cantadas em inglês e a atitude de manter toda a produção sob seu controle.

Nos anos 1990, pós-surgimento do Nirvana, há uma mudança nas estratégias das majors nos Estados Unidos, que criam seus selos para escoar uma produção chamada "alternativa" com bandas mais experimentais direcionadas a um público ligado a uma cena local e que movimentavam cenários musicais específicos. No Brasil ocorre o mesmo fenômeno com selos dentro de majors coordenados por nomes conhecidos da indústria fonográfica, como Pena Schimidt, que lançou o Tinitus, apoiado pela Polygram; Carlos Savalla, com o Plug, apoiado pela BMG; Carlos Eduardo Miranda, com o Banguela; Dado Villa-Lobos, com o Rock It, dentro da EMI. Neste contexto entre a ascensão da axé music, a hegemonia do BRrock, a proliferação de selos independentes no Brasil e a busca de gravadoras por bandas que poderiam fazer o mesmo sucesso que o Nirvana, a brincando de deus não fecha com nenhum selo

8 A axé music é o encontro da música de blocos de trio elétrico com a música de blocos afro (frevo baiano + sambareggae). É um estilo mestiço cuja linguagem mistura sonoridades harmônicas e percussivas (GUERREIRO, 2000, p. 133). 9 Festival de Música Independente da Bahia, que aconteceu nos anos de 1997 e 1998. Ocorrendo outro somente em 2007. 
e busca o seu espaço de forma independente. Uma das principais características da banda, referenciada por seus fãs e enaltecida por críticos musicais, é a opção em fazer tudo de forma independente, manter-se fiel ao canto em inglês, o que significava menos espaço no mercado de rock do Brasil, ter controle sobre o produto e afirmar esta liberdade criativa através de um experimentalismo estilístico. Estas atitudes fizeram a brincando de deus virar um ícone desta primeira geração indie rock nacional, por sua aclamada resistência ao mainstream.

Ao se posicionar como uma banda de indie rock, que canta em inglês, tem seu próprio circuito de shows e nega um cenário musical estabelecido, a brincando de deus passa a ser reconhecida por este potencial significativo. Desta forma, se reposiciona e se recontextualiza no mercado do rock com seus valores de banda independente, que usa formas alternativas de divulgação, que se apresenta em um circuito pequeno e disponibiliza para fãs, críticos, produtores uma outra forma de consumo musical. Não por acaso, ganha espaço em tradicionais meios de comunicação, como a Folha de S. Paulo, o que possibilita outras leituras sobre a cena musical da Bahia. O vínculo que a brincando de deus cria com o gênero cultural e seu público fez com que o terceiro e último disco, brincando de deus (2000), fosse eleito pelo jornalista Alexandre Matias (2006) como um dos 25 fundamentais na formação de um mercado independente, tanto do ponto de vista comercial como artístico. "Um disco que poderia ser lançado no mercado exterior sem dificuldades e que, apesar da anglofilia, é essencialmente brasileiro". (MATHIAS, http://www.oesquema. com. br/ trabalhosujo, 23/03/2006).

O terceiro e último disco da banda foi coproduzido por André T., produtor baiano com diálogo com a música eletrônica, ao mesmo tempo, a banda gravou no Estúdio WR, templo dos artistas da axé music. O estúdio de Wesley Rangel, WR, tem história na ascensão da música baiana, já que foi responsável pela tecnologia que permitiu a gravação dos tambores dos blocos afro, como o Olodum. Gravar e mixar o álbum em um estúdio símbolo da axé music está ligado ao perfeccionismo da banda com qualidade técnica e a experiência de Nestor Madrid, engenheiro de som, responsável pelos principais lançamentos da música baiana nos anos 1980/1990. O convite para André T. ser o coprodutor aponta para uma relação com timbragens eletrônicas e mais experimentalismo. O disco ainda conta com a participação de músicos de formação acadêmica, como Alex Pochat, e da cena rock local, como Morotó Slim (Retrofoguetes) e Paulinho (Cascadura). O álbum foi gravado logo após a banda perder instrumentos, equipamentos e material de divulgação em um incêndio causado por um curto-circuito no estúdio do grupo. A brincando dialoga com outros gêneros e fortalece a ideia que cerca o indie rock como um gênero híbrido, o que faz com que a banda experimente sonoridades como reggae, música eletrônica e psicodelismo sem afetar seus traços musicais mais relevantes: riffs de guitarra, solos minimalistas, distorções e a baixa fidelidade.

$O$ resultado de uma sonoridade em baixa fidelidade ou low-fi é uma busca estética, como explica Fraga: "Um tipo de gravação com menos qualidade, meio aguda e ruidenta, com o uso da voz abafada nos grupos de rock (....). Esse tipo de equalização é encontrada facilmente entre os grupos que se aproximam da cena indie". (2007, p.17). A sensação é como se escutasse a banda ao vivo, com imperfeições e com os vocais mais baixos, os instrumentos são distorcidos e as microfonias fazem parte da sonoridade. Traços que marcaram o que se rotulou como indie rock nos anos 1980 e que são incorporados nas gravações da brincando de deus, mesmo com o alto padrão técnico do estúdio. Estão presentes nas 14 faixas, as melodias requintadas, os vocais entediados e pouco emocionais do vocalista Messias em canções que soam ruidosas com distorções barulhentas, muitas vezes que têm por trás a opção de uma poética de baixa fidelidade, o que amplifica as microfonias.

\section{Considerações finais}

O fundamental neste artigo foi buscar lançar luz, a partir de duas bandas, de como o indie rock articula a ideia do que é rock "autêntico" e toma para si essa posição, especificamente nos anos 1980 e 1990. Podemos perceber que as duas bandas que discutimos neste artigo buscam apuro técnico e artístico se filiando a uma certa ideia de "obra-prima", uma expressão artística 
em que procuram a perfeição dentro do rock. Esta posição é uma reivindicação de articidade que passa pelo minimalismo musical na qual o menos é mais, uma volta a um rock cru, ao básico, sem virtuosismos, com vocalistas que cantam fora do tom, guitarras distorcidas. São posições (ideológicas, sociais, artísticas) que remetem à ideia do indie rock como uma expressão artística e ao que fazia a Velvet Underground nos anos 1960, quando incorporou elementos da pop art nos seus shows e discos. O indie rock tem suas raízes no pós-punk, mas também na forma como desafia o rock estabelecido e a indústria fonográfica. Ele quer ser independente, não quer fazer parte do mainstream, ou seja, quer sua liberdade criativa para fazer canções que permitam o estranhamento de vozes desafinadas, as guitarras distorcidas, a distância do virtuosismo, as letras intelectualizadas e o desejo em transformar o conjunto do seu trabalho em uma "obra musical" e ter sua condição de artista reconhecida dentro de um mercado de nicho.

Neste artigo, usamos a ideia de gênero da maneira como é vivenciado pelas comunidades musicais, como uma forma de descrever o seu conteúdo, ou seja, gênero como uma categoria cultural. Como sugerem autores como Frith e Fabbri, optamos por pensar o gênero em uma perspectiva social, econômica e ideológica, o que também não impede que suas definições sejam imprecisas, mas nos ajuda a entender por que a experiência que é definida como indie rock é compartilhada por fãs, músicos, produtores e críticos como uma prática musical. A audiência se articula a partir de um conhecimento especializado de uma determinada biblioteca do rock, que o posiciona como uma música intelectual, erudita, que permite uma estratificação e vai servir às necessidades sociais de determinados grupos que vão construir o discurso de independência do indie rock. Ao ser forjado como um rock independente que valoriza a liberdade criativa, cria-se uma rede formada por selos, lojas, programas de rádio, blogs, redes sociais que atinge pontos de identificação simbólica. Ao mesmo tempo, sua sonoridade vai sendo construída a partir dos seus meios de produção (BANNISTER, 2006), com gravações em estúdios caseiros, uso de instrumentos e equipamentos baratos, circulação por uma rede alternativa que permite que distorções, dissonâncias e gravações com baixa qualidade, sejam classificados como marcadores da sua liberdade criativa por artistas, produtores e audiência.

Quando se julga uma música como indie rock, é preciso compreender o que está sendo inferido com este juízo de valor. Frith (1996) coloca que para acontecer este julgamento são necessários determinados conhecimentos, sempre a partir das formas culturais conhecidas. $\mathrm{Na}$ música, Frith coloca que isso se dá a partir de três grupos sociais: músicos, produtores e consumidores que formam uma comunidade de conhecimento. Essa comunidade vai estabelecer regras, habilidades, valores para entender o que é original, o que é autônomo, o que é criativo. Para Frith, o julgamento sobre o processo musical sempre dependerá de vários tipos de conhecimento social, cultural, político, ideológico, estético. "Nós precisamos conhecer (ou saber sobre) o original; para descrever uma canção como 'padronizada', entender o que estamos ouvindo (ou não) em outras canções similares" (FRITH, 1996, p. 70). Neste artigo, a questão não é afirmar que o indie rock é um gênero em sentido estrito ou não, mas a utilização da ideia de gênero cultural por parte de críticos, de fãs, de músicos que permitem a uma comunidade de conhecimento afirmar que determinadas identificações se posicionem, vivam certas experiências afetivas e políticas como a reivindicação de autonomia criativa em meio ao processo de produção serial da indústria musical.

\section{Referências}

BANNISTER, Mathew. White boys, white noise: masculinities and 1980s indie guitar rock. Hampshire: Ashgate, 2006.

DIAS, Márcia Tosta. Os Donos da Voz: Indústria Fonográfica Brasileira e Industrialização da Cultura. São Paulo: Boitempo, 2000.

ENO, Brian. The Studio is Compositional Tool. In: COX, Christopher; WARNER Daniel. Audio Culture. Londres: Continuum Books, 2004. 
FABBRI, Franco. A Theory Musical Genres: Two Aplications. Trabalho apresentado na First International Conference on popular Music Studies. Amsterdã, 1980.

Tipos, categorias, géneros musicales. Hace falta una teoria? Conferência de abertura da International Association for the Study of Popular Music (IASPM). Havana. 2006.

FLANAGAN, Bill. Dentro do Rock, o que eles pensam e como criaram suas músicas. Rio de Janeiro: Marco Zero, 1986.

FRAGA, Danilo. O beat e o bit do rock brasileiro: internet, indústria fonográfica e a formação de um circuito médio para o rock no Brasil. Revista da Associação Nacional dos Programas de PósGraduação em Comunicação (E-COMPÓS). 2007.

FRIEDLANDER, Paul. Rock and Roll, uma história social. Rio de Janeiro: Record, 1996.

FRITH, Simon. La industria de la música popular. In: FRITH, Simon; STRAW, Will; STREET, John (Orgs.). La Otra História del Rock. Barcelona: Ma Non Troppo, 2001.

FRITH, Simon. Performing Rites: On the Value of popular Music. Massachusetts: Cambridge. Harvard University Press, 1996.

Popular Music: music and identity.

USA/Canadá: Routledge. 2004.

GOMES, Itania; ARAÚJO, Valéria. (2015) “Ai, que infortúnio!” Disputas de gênero em um produto da indústria pop. In: SÁ, Simone Pereira de; CARREIRO, Rodrigo; FERRARAZ, Rogério. Cultura Pop. Salvador/Brasília: Edufba/Compós

GOMES, Itania. Efeito e Recepção: a interpretação do processo receptivo em duas tradições de investigação sobre os media. In: GOMES, Itania; JACOB, Maria Carmem Souza. Media \& Cultura. Salvador: EDUFBA. 2003.

GUERREIRO, Goli. A Trama dos Tambores. São Paulo: Editora 34, 2000. institutional politics and aesthetics of a popular music genre. Cultural studies, vol. 13 (1), p. 3461, 1999.

JANOTTI JÚNIOR, Jeder; CARDOSO, Jorge Filho. A Música Popular Massiva, o mainstream e o underground - trajetórias e caminhos da música na cultura midiática. In: JANOTTI JÚNIOR, Jeder; FREIRE FILHO, João. Comunicação $e$ Música Popular Massiva. Salvador: EDUFBA, 2006.

MARTÍN-BARBERO, Jesus. Dos meios às mediações. Comunicação, cultura e hegemonia. Rio de Janeiro: EDUFRJ, 2001.

SADIE, Stanley. Dicionário Groove de Música. Rio de Janeiro: Jorge Zahar. 1988.

SHUKER, Roy. Vocabulário de Música Pop. São Paulo: Hedra, 1999.

Revistas, sites e jornais

ABEBE, Nitsuh, Pitchfork, Sonic Youth Daydream Nation: Deluxe Edition, em http://pitchfork. $\mathrm{com} /$ reviews/albums/10326-daydream-nationdeluxe-edition/13/06/2007. Acesso em dezembro de 2010 .

CASTRO, Chico. Três Vezes Messias. In: rockloco. blogspot.com/2010/03/tres-vezes-messias.html, em 16/03/2010. Acesso em maio de 2010.

DODÔ, Os perdedores, 19/11/2010, O Esquema, http://www.oesquema.com.br/ trabalhosujo/2010/11/19/os-perdedores.html. Acesso em março de 2011.

FORTINO, Leandro. Os cinco melhores discos do Youth Sonic. In: Jornal Folha de S.Paulo, Caderno Folhateen, 10/07/2006, em http://www1.folha. uol.com.br/fsp/folhatee/fm 1007200614 .htm. Acesso em fevereiro de 2011.

LIMA, Carlos Eduardo. Tenn Age Riots, http://www.interney.net /blogs/ blogdocel/?s=sonic + youth\&submit=Go, $\quad \mathrm{em}$ 17/06/2009. Acesso em janeiro de 2011. 
Cazzo Entrevista, 25/03/2009. Acesso em agosto de 2010.

MATIAS Alexandre. O Esquema, 23/03/2006, em http://www.oesquema.com.br/trabalho sujo/ 2006/03/23/indie-25.html. Acesso em abril de 2009.

MATOS, Luciano. A volta do brincando de deus In: http://www.nemo.com.br/elcabong/?p=2359. A cesso em fevereiro de 2011.

PALMER, Tobert, Sonic Youth, Daydream Nation, In: Rolling Stone/ http: //www. rollingstone.com/ music/ album reviews/ daydream-nation-19890112 janeiro de 1989. Acesso em novembro de 2010.

POWELL, Mike, Pitchfork, The Velvet Underground. In: http://pitchfork.com/reviews/ albums/13807-contra/ http://www.rollingstone. com/ music/artists/the-velvet-underground/ biography, em 11/01/2010/. Acesso em novembro de 2009.

REVISTA ROLLING STONE. Sonic Youth volta à independência, em 14/09/2008, em http://www.rollingstone.com.br/secoes/novas/ noticias/3487/. Acesso: janeiro de 2011.

RODRIGUES FILHO, Elias. Daydream Nation - Sonic Youth In: 16/11/10/ WHIplash/ http:// whiplash.net/materias/db/118822-sonicyouth. html21/06/2007. Acesso em abril de 2009. 